\title{
Training of Intelligent Maintenance Talents for the Mechanical Specialty for Intelligent Manufacturing
}

\author{
Xiaoyun Gong \\ School of Mechanical and Electrical Engineering \\ Zhengzhou University of Light Industry \\ Zhengzhou, China \\ Hongwei $\mathrm{Li}^{*}$ \\ School of Mechanical and Electrical Engineering \\ Zhengzhou University of Light Industry \\ Zhengzhou, China
}

\author{
Guofu Luo \\ School of Mechanical and Electrical Engineering \\ Zhengzhou University of Light Industry \\ Zhengzhou, China \\ Changjun $\mathrm{Wu}$ \\ School of Mechanical and Electrical Engineering \\ Zhengzhou University of Light Industry \\ Zhengzhou, China
}

\begin{abstract}
Intelligent maintenance in machinery production is part of intelligent manufacturing. The intelligent construction of the manufacturing industry is an integral part of the training of professional intelligent maintenance personnel. The paper focuses on the analysis of mechanical professional intelligent maintenance, which can have deeply impacted on manufacture, equipment life cycle management and maintenance, performance prediction and optimization of the intelligent devices. It also discusses the necessity of cultivating intelligent maintenance professionals in the discipline of mechanical engineering. A competency model for intelligent maintenance professionals in the new engineering discipline is proposed, and designs the basic curriculum system according to the model.
\end{abstract}

Keywords-Intelligent manufacturing; Engineering; Intelligent maintenance; Talent training

\section{INTRODUCTION}

Intelligent manufacturing is characterized by digitalization, networking and intelligence in manufacturing, and is an important theme and core technology of "China Manufacturing 2025". Intelligent manufacturing makes full use of the combination of information and communication technology and Cyber-Physical Systems (CPS) to transform the manufacturing industry to intelligent[1]. Intelligent maintenance and equipment health management are an important new model in intelligent manufacturing. Intelligent maintenance, equipment management is an important new model in Intelligent manufacturing, which is the monitoring, diagnoses, predicts, and management of the status of complex and critical industrial equipment and systems. And provides important technical support for the operation and management of the enterprise, and the health management level of the entire product life cycle, as well as the reliability of major equipment [2]. With the localization of aerospace, high-speed rail, electric power and other equipment technologies, the transformation of enterprise information and intelligence, it is required to ensure the normal operation of equipment in accordance with requirements such as "data maintenance", "precise maintenance", and "remote diagnosis and maintenance." It

Henan Higher Education Teaching Reform Research and Practice Project (No. 2019SJGLX059Y); Young Backbone Teachers in Henan Province (No. 2018GGJS091) provides important means for the company's operation management and health management level of the entire product life cycle, as well as the reliability of major equipment.

The "Manufacturing Talent Development Planning Guide" points out that a new generation of intelligent manufacturing will lead a new round of industrial revolution. It is necessary to strengthen the training of composite professional talents and promote the establishment of new mechanisms for crosscollege, interdisciplinary, and cross-professional cross-training in colleges and universities[3]. Colleges and universities should follow the trend, integrate and optimize the teaching resources of different disciplines from the professional level, increase the depth, breadth and system of cross-integration of intelligent manufacturing teaching. In order to cope with the new development trend of "China Manufacturing 2025", train advanced application-oriented talents in intelligent maintenance of mechanical disciplines that are suitable for the development of intelligent manufacturing.

\section{BACKGROUND TO PROMOTE THE DEVELOPMENT OF INTELLIGENT MAINTENANCE}

\section{A. Intelligent Manufacturing}

Intelligent manufacturing is a comprehensive crossover technology that studies information perception and analysis, knowledge expression and learning, intelligent decision-making and execution in manufacturing activities[4]. Manufacturing activities that involve design, production, management, and service in the product's entire life cycle, as shown in Fig. 1. Intelligent manufacturing is the deep fusion of advanced manufacturing technology and new generation of information technology. It covers advanced manufacturing, intelligent control, big data acquisition and analysis, etc. It not only runs through every link of the whole life cycle of products, manufacturing, services and the integration of manufacturing systems, but also realizes the digitalization, networking and intelligence of manufacturing, improves the product quality, corporate profitability, service level, promotes the innovative 
development, green development, harmonious development, open development and Shared development of manufacturing.

\section{Full Life Cycle}

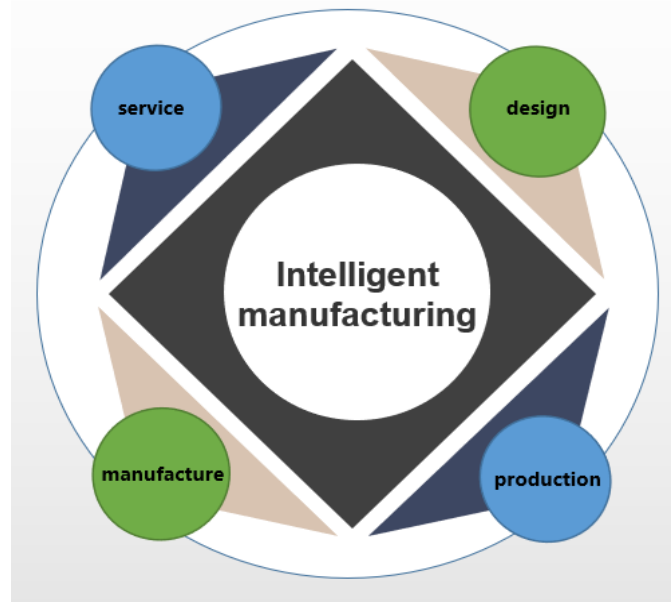

Fig. 1. The full life cycle of intelligent manufacturing

\section{B. Intelligent Maintenance and Equipment Health Management}

Intelligent maintenance refers to collecting equipment operation data, uploading the data to the enterprise data center, building system software to monitor and control the equipment in real time online, and performing data analysis for equipment performance evaluation, life prediction, remote fault diagnosis and maintenance management. "Implementation Guide for Intelligent Manufacturing Engineering (2016-2020)" puts forward specific requirements for intelligent maintenance:

1) A standardized information collection and control system, an automatic diagnosis system, a fault prediction model based on an expert system, and a fault index knowledge base shall be built.

2) It can realize remote unmanned control of equipment, early warning of working environment, monitoring of operating status, fault diagnosis and self-repair.

3) Product life cycle analysis platform, core parts life cycle analysis platform and user usage information model were established.

4) It can provide services such as health status monitoring, virtual device maintenance plan formulation and execution, optimal use plan push, and innovative application opening for intelligent equipment[5].

"Data maintenance", "precise maintenance", "remote diagnosis and maintenance" have become important signs of intelligent manufacturing.

\section{TALENT REQUIREMENTS FOR EQUIPMENT INTELLIGENT MAINTENANCE}
A. Industry Demand
Under the guidance of intelligent manufacturing, the setting of corporate positions changes with the advancement of

intelligent manufacturing. Intelligent production enterprises and intelligent equipment manufacturing enterprises use data to replace experience and use data optimization solutions to promote the improvement of enterprise quality. It is hoped that intelligent construction can improve the fine quality management level. With the improvement of automation and informatization, the maintenance and maintenance of equipment has been transformed from traditional passive maintenance to "state-based equipment maintenance" and "equipment-based equipment maintenance" remote state-based equipment maintenance. The entire production process guides the normal operation of equipment based on the results of big data analysis, and traditional low-skilled equipment maintenance positions have been gradually eliminated. Cultivation of innovation awareness is a new requirement for intelligent production. The level of automation of the production process needs to be continuously improved to improve efficiency. This requires continuous improvement of cutting-edge technologies in the field of intelligent manufacturing engineering, with innovation awareness and interdisciplinary cognitive fusion capabilities.

\section{B. Talent Demand}

In the intelligent manufacturing process, the role of humans has changed from service providers and operators to planners, coordinators, evaluators, and decision makers. To achieve the goal of "China Manufacturing 2025", manufacturing personnel are required to have not only basic theories and expertise in mechanical manufacturing and automation, but also master information technology, intelligent sensing technology, industrial robot technology, internet of things technology, and machine learning intelligent expertise such as technology. Compound talents with modern information technology, intelligent equipment technology, and independent completion of intelligent goals and tasks will be the new favorite of enterprises. At the same time, enterprises have higher requirements for the quality of talents, such as "data maintenance talents", which require the rapid completion of equipment maintenance and maintenance under the guidance of data information, and they also require employees to have expertise in intelligent manufacturing. Enterprises need multidisciplinary talents who are professional, intelligent and capable. According to the "Research Report on Digital Economy and Talent Development in the Yangtze River Delta" released by the School of Economics and Management of Tsinghua University, the number of digital talents in the Yangtze River Delta in China reached 118,000. Digital talents are professional and complementary talents in information technology. They are the "main force" for the development of multiple fields such as big data, "Internet +", artificial intelligence, and intelligent manufacturing. But as of 2018, there has been a gap of more than 5 million people in the demand for artificial intelligence in China [6]. In terms of training artificial intelligence talents in China, there is a large gap between market demand for talents. At present, major universities urgently need to strengthen the training of digital talents and improve the training system has become the consensus of the industry. 
manufacturing specialty. In order to cope with the new development trend of "China Manufacturing 2025", it is necessary to train technical and technical talents suitable for the development of emerging industries.

With the continuous development of the intelligent manufacturing industry, the development of intelligent manufacturing has put forward new requirements for the cultivation goals and positioning of colleges and universities. At present, most of the current talent training programs and curriculum systems in engineering universities are based on traditional subject knowledge frameworks. The training scheme and teaching philosophy of traditional mechanical engineering disciplines are based on the needs of Industry 3.0. The interdisciplinary curriculum system is relatively lacking, and there is a shortage of talents who are digitized, networked, intelligent, and advanced manufacturing technologies. The education model is difficult to train talents who can manage the increasingly complex and comprehensive manufacturing system and cannot keep up with the development needs of the intelligent manufacturing industry [7-8]. There is still a long way to go between the professional setting and the industrial structure of intelligent manufacturing. The existing intelligent manufacturing teaching resources are scattered in different subject areas, and each discipline often starts from its own discipline characteristics for professional construction. The interdisciplinary curriculum system is relatively lacking, and the practical teaching curriculum lacks innovative topics related to the development of emerging manufacturing industries.

\section{THINKING AND EXPLORATION OF TALENT TRAINING}

\section{A. Construction of Training Mode}

\section{1) Reasonable positioning of training goals}

Intelligent manufacturing involves many new technology fields. In terms of professional setting and training mode, humans should combine the needs of intelligent manufacturing industry with intelligent talents, build a scientific and reasonable interdisciplinary training mode, cultivate the digital thinking ability and innovation ability of engineering noncomputer major students. The existing cross-integration of colleges and universities is basically based on scientific research. Through extracurricular scientific and technological activities and scientific research project training, a crosscooperation mode of students and teachers of different disciplines is formed. The effect of cross-convergence depends entirely on the platform construction and research development of the scientific research team. In order to form a comprehensive and systematic cross-scientific knowledge system and practice system, to promote students to systematically acquire professional knowledge in the field of intelligent manufacturing, and to train innovative talents who master and integrate multidisciplinary knowledge. It is necessary to integrate and optimize the teaching resources of different disciplines from the professional level, redefine the depth, breadth and system of the cross-integration of intelligent manufacturing teaching. At the same time, teachers are encouraged to conduct in-depth corporate research, analyze changes in corporate positions and talent needs. Based on the actual situation of colleges and universities, build a smart manufacturing talent training program related to the machinery
2) Use artificial intelligence technology to build a teaching platform

Under the traditional talent training model, the teaching tasks are heavy and the work repetition rate is high. Teachers' repeated teaching and student mechanical learning require a lot of time. Using artificial intelligence to build a teaching platform for smart campuses. Teachers can use artificial intelligence software to perform online testing, virtual simulation experiments, and real-time academic monitoring of students. Teachers can also analyze the distribution of knowledge points of the curriculum and the distribution of students' learning based on the analysis of relevant data, and respond to the learning needs of students in a timely manner. In the context of intelligent learning, teachers not only need to be proficient in using artificial intelligence tools and fully understand the "integrated artificial intelligence and education" model, but also need to work hard to build a new model of talent training under the artificial intelligence platform and explore new models of education governance in the information age. In this way, students can be effectively guided to understand the activities of artificial intelligence, and it is conducive to the training of students' creative thinking ability.

\section{B. Identify Improve Course System Construction}

According to the new requirements of intelligent manufacturing and the characteristics of the professional development of mechanical manufacturing, combined with the software and hardware teaching conditions of the school and college, the professional courses of mechanical manufacturing are reasonably set up. Adopting a curriculum system that combines "professional basic courses, specialized courses, and innovative elective courses". According to different professional directions, construct professional course modules with obvious characteristics of intelligent manufacturing. Then students can choose a certain direction for deep learning according to their own individual advantages, forming a crosscomplex curriculum system with professional characteristics. materials is based on the requirements of relevant new engineering of intelligent manufacturing. For example, courses such as "Intelligent Robot", "Intelligent matter Federation", "Intelligent maintenance" can be offered. Among them, the construction of intelligent maintenance should focus on intelligent sensing and detection technology, fault diagnosis technology, signal analysis and processing, pattern recognition, depth learning and so on. Due to the limited class hours, how to effectively integrate mechanical manufacturing courses and intelligent courses in the existing training system, it is necessary to make full use of the MOOC platform and the school intelligent teaching platform to integrate the highquality information resources such as simulation, MOOC, micro-courses, excellent courses and so on, so as to use them for teaching and improve the learning effectiveness of students. Updating the teaching content and improving relevant teaching 


\section{REFERENCES}

\section{CONCLUSION}

The realization of intelligent manufacturing requires a large number of high-level applied talents capable of using information technology and making production and management on the basis of big data. The development of "data maintenance talents", which can quickly complete the operation, maintenance and performance prediction of equipment under the guidance of data information, has become a part of intelligent manufacturing. Under the guidance of the state's vigorous development of intelligent manufacturing policies, that not only vigorously promote the cultivation of intelligent maintenance talents and intelligent manufacturing talents in mechanical manufacturing majors, but also locate reasonable training goals, optimize the curriculum system, build an intelligent teaching platform, and provide the highquality teaching environment for the training of mechanical manufacturing intelligent maintenance talents.

\section{ACKNOWLEDGMENTS}

This research was supported by Henan Higher Education Teaching Reform Research and Practice Project,(No. 2019SJGLX059Y), and by Young Backbone Teachers in Henan Province (No. 2018GGJS091).
[1] F. Tao, Q.L. Qi, "New IT-driven service-oriented smart manufacturing: framework and characteristics,” IEEE Transaction on Systems, Man and Cybernetics: Systems, DOI: 10.1109/TSMC. 2017.

[2] X.F. Chen, Y. Y. Zi, "Intelligent maintenance and health management (In Chinese),” Beijing: Machinery Industry Press, 2018.

[3] "Manufacturing talent development planning guide,” http://www.moe. gov.cn /jyb_xwfb/s7600/201702/t20170214_296155.html(In Chinese), 2017.

[4] Chinese Mechanical Engineering Society. "China's Mechanical Engineering Technology Roadmap for 2030(In Chinese)," Beijing: China Science and Technology Press, 2013.

[5] "Intelligent Manufacturing Engineering Implementation Guide (20162020)," http://www.doosansmart.com/News/ 104.html (In Chinese), 2015.

[6] People's Daily People's Comment: Artificial Intelligence, Seeing Trends and Demands, http://opinion.people.com.cn/n1/2019 / 0911 / c100331347509.html (In Chinese), 2019.

[7] L.W. Wang, G.F. Luo, W.L. Du, et al. "Study and practice of applicative talents development scheme with features of light industry machinery specialty," 2015 International Conference on Advanced Education and Management. Guilin, May 2015, pp. 259-264.

[8] X.F. Chen, S. B. Wang, B.J. Qiao, Q. Chen, "Basic research on machinery fault diagnostics: Past, present, and future trends," Front. Mech. Eng., Vol 13, 2018, pp. 264-291. 